\title{
correspondence
}

\section{Missing academicians}

SIR,--The collective letter of 72 members of the USSR Academy of Sciences condemning the activity and stands of Andrei Sakharov (Izvestia, October 26) is worth analysis. According to World of Learning (1974-75 edition), the academy has 236 full and 445 corresponding members, that is, 671 in total. This means that only about $10 \%$ of the academy's members put their signatures on the anti-Sakharov statement.

The list of signatures does not contain the majority of the most famous academicians-physicists, who no doubt know better than others Sakharov's scientific and moral qualities. Among those physicists who did not sign the statement were P. L. Kapitsa, Bogolyubov, Migdal, Lifshitz, Zeldovich, Pontecorvo, Leontovich, Ginzburg, Budker, Belyaev, Frank, Cherenkov, Kadomtsev, Khariton, Kikoin, Linnik, Sagdeev and Vernov,

Similarly, we could not find among the 72 academicians the signatures of such leading Soviet mathematicians as Kolmogorov, P. S. Alexandrov, A. D. Alexandrov, Petrovskij, Pontryagin, Sobolev, Vinogradov, Kantorovich, Gclfand and Shafarevich.

In addition, the statement was not signed by T. Lysenko and M. Sholokhov. All told, the anti-Sakharov statement is much more a testimony concerning the real situation and moods in the Soviet Academy of Sciences than a simple condemnation of Andrei Sakharov.

Research Institute for Physics,

\section{F. J $\mathrm{ANOUCH}$}

Stockholm

\section{Crisis in Italian universities}

SIR,-The article by Gillian Boucher entitled "Continuing crisis in Italian Universities" (November 20, p190) should, I feel, be completed by a few comments to give a fair representation of the situation. The comments which follow are based mainly on the situation in most of the Departments of Physics in Italy (which I do know from personal experience) but can apply with minor changes to almost all the faculties; the problems of Law, Engineering and Medical Sciences are similar in some respects, but different in others.

The central point of the article, namely that the Italian universities are in a state of agony, is correct, and this may, after all, be the only fact of general interest to your readers. It is also true that, due to a set of demagogic laws, any student can rather easily get his final degree; this is not stated explicitly in the article, but can perhaps be inferred.

What is omitted altogether is the fact that the demagogic laws mentioned above achieved the intended aim of introducing into practically permanent staff positions a large number of people with no scientific qualification but disposed to aggressive political activity $(95 \%$ or more of them are leftists). This is the main reason why, in spite of the present political turbulence, the invasion of departments is much less frequent than it used to be a few years ago: those who invaded or stimulated the invasions now have permanent positions inside.

This process, in addition to depressing the average scientific level in many departments to unbelievably low values, has filled each department with large numbers of "teachers" or post-doctoral "research workers". They teach or do research only in Marxism, or, to be generous, in some cases, in Science and Society. To give an example, the number of staff members with an office in the Department of Physics in Genoa is ninety-five; the total number of students in Physics, covering all the four years of the curriculum, is approximately the same. Some teachers do not have any students at their courses.

This overcrowding of "democratic" but ignorant staff members in the departments has three important consequences:

- those people who have obtained their positions fighting against "meritocracy" continue to dedicate all their activity to similar issues;

- they reproduce themselves;

- they occupy, for ever, a large number of positions.

In these conditions no brilliant young man has a chance of finding even a temporary position in the university.

These remarks show, I hope, that the main problems of the Italian universities are not of money (which is, however, badly administered), nor the fact that the full professors try to conserve their privileges (as one of the privileged I would like very much to know from your correspondent what my privileges are). The main problems are the demagogic and antimeritocratic edicts which were strongly supported for many years by the Corriere della Sera (to which Gillian Boucher refers). It is a well known tactic of disruption to destroy something first and then to complain about how badly it works.

Giacomo Morpurgo

Department of Physics,

University of Genoa, Italy

\section{Kennedy's deed}

SIR,-You include a comment (November 6, p5) entitled “Kennedy's good deed" regarding the U.S. Senate vote to ban the use of diethylstiboestrol as cattle feed supplement. A number of controversial matters are introduced into this short article, but I wish to protest the attribution of purely political motives to Senator Kennedy's sponsorship of this bill. Those of us who know of Senator Kennedy's past efforts on behalf of cancer research in this country must consider these remarks both unfair and uncalled for. One would hope for much higher standards from Nature.

George P. Studzinski

New Jersey Medical School,

Newark, New Jersey

\section{Stockport to Darlington?}

SIR,-I have just seen your issue of September 25 , in which you quote from an 1875 Nature in $A$ hundred years ago. The extract deals with the opening of the first railway, but refers to the line "between Stockport and Darlington". Is this a 100-year-old misprint, or one perpetrated as recently as September 1975?

I am reliably informed that it is not even today possible to go from Stockport to Darlington direct: the trip necessitates two changes of train and takes 3-4 hours. The distance between Stockton and Darlington, which gave Stephenson's railway its correct name, is 30 miles or so.

\section{B. Jove}

Hove, UK

Unfortunately the error was made in 1875 , and has been faithfully reproduced! -ED.

\section{Box and Cox}

SIR,-Cox (August 14, p524) writing on Box! You're having us on.

Medical Research Council,

R. S. BRAY

The Gambia 